\title{
ANÁLISE DA SECAGEM CONVECTIVA DE TECIDOS DE ALGODÃO E POLIÉSTER
}

\author{
C. M. CANEDA ${ }^{1 *}$, M. C. FERREIRA ${ }^{2}$ \\ ${ }^{1}$ Universidade Federal de São Carlos- Programa de Pós-Graduação em Engenharia Química, \\ ${ }^{2}$ Universidade Federal de São Carlos- Departamento de Engenharia Química \\ *e-mail: chaianemessa@gmail.com,mariaf@ufscar.br
}

\begin{abstract}
RESUMO
Neste trabalho é apresentada uma análise da secagem convectiva de três tipos de tecidos comerciais: algodão do tipo atoalhado, algodão do tipo jeans e o poliéster, visando avaliar como ocorre o processo de secagem nos diferentes tipos de tecido. Dentro desse contexto, buscou-se analisar a secagem convectiva em diferentes condições para os três tipos de tecidos, verificando como a secagem ocorre em cada material. A secagem convectiva foi realizada em um secador de túnel de convecção forçada com velocidades ajustadas de 1 e $2 \mathrm{~m} / \mathrm{s}$ e temperaturas de 50,60 e $70^{\circ} \mathrm{C}$. Nos resultados obtidos, para os materiais que apresentaram o período de taxa decrescente, foram aplicados na cinética de secagem a metodologia de curvas generalizadas e então, feito ajustes de equações de cinéticas de secagem disponíveis na literatura, sendo que a equação de Page modificada representou melhor os resultados experimentais.
\end{abstract}

\section{INTRODUÇÃO}

A indústria têxtil é um dos setores que representa uma imensa importância na economia global de hoje e emprega intensiva mão-de-obra a baixo custo.

As indústrias têxteis e de vestuário constituem, juntas, a quarta maior atividade econômica mundial. "Em valores monetários, a cadeia têxtil-vestuário brasileira produziu, em 2005, 32,7 bilhões de dólares, o que equivale a $4,1 \%$ do PIB total brasileiro e a 17,2 \% do PIB da indústria de transformação" (Firjam e Ferraz, 2011).

Na produção de um artigo têxtil, na etapa de beneficiamento, toda fibra é convertida em fios. Nessa fase do processo, a secagem térmica é uma etapa primordial. Nessa etapa, são utilizados meios convencionais para a secagem de tecidos (vapor, gás natural e infravermelho), em que os secadores podem ser condutivos ou convectivos.

Sendo assim, uma análise da secagem de tecidos associada às características das fibras têxteis, tanto para as fibras naturais (algodão) como as sintéticas (poliéster), pode indicar como otimizar a energia gasta nesse processo, visto que este insumo é de elevado custo e bem representativo para as indústrias em geral.

Existem diferentes categorias de tecidos. Os classificados como tecidos planos (Figura 1), são compostos por uma estrutura típica: entrelaçamento de vários fios de urdume e um único fio de trama, sendo que os fios de urdume determinam o tipo de tecido.

Figura 1- Estrutura do tecido plano: entrelaçamento tela

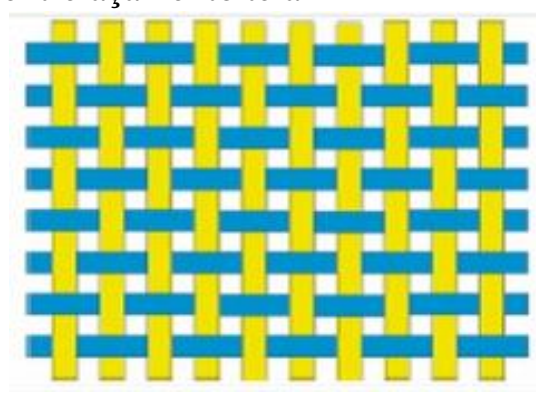

Fonte: SCERI, (2015).

Para o desenvolvimento da maioria dos artigos têxteis, a fibra é a principal matéria- 
prima utilizada. As fibras têxteis podem ser divididas em dois grandes grupos denominadas fibras naturais e sintéticas. Nas primeiras, incluem-se o algodão e linho, fazendo a lã, seda e poliéster, parte do segundo grupo.

A fibras sintéticas, tais como o poliéster, apresentam elevada resistência à absorção de umidade e grande resistência à tração. Já as fibras naturais têm como vantagens a facilidade de absorção de umidade e boa condutividade de eletricidade estática. Porém deve-se levar em conta o cuidado com o controle da temperatura no processo de secagem, pois além de acarretar danos ao tecido, se realizada incorretamente pode provocar o desenvolvimento de microrganismos nas fibras (ALBUQUERQUE, 2011).

Em virtude da escassez de resultados e informações nessa área, é importante a realização de estudos envolvendo a secagem desse tipo de material.

As fibras naturais e sintéticas são muito utilizadas comercialmente e possuem comportamentos distintos no que se refere à capacidade de absorção de água. Além da composição, o tipo de trama define a forma de contato entre as fibras e, portanto, influencia nos processos de transferência de calor e massa que ocorrem no tecido durante a secagem. $\mathrm{O}$ objetivo do presente trabalho é analisar o processo de secagem convectiva para os três tipos de materiais (atoalhado, jeans e poliéster).

\section{METODOLOGIA}

\subsection{Materiais e métodos}

Os tecidos, tanto de algodão como o de poliéster, foram adquiridos no mercado local na cidade de São Carlos-SP. Foram cortadas amostras de $8 \times 8 \mathrm{~cm}$, cuja umidade inicial variou de 0,80 a 5,0 (b.s).

Antes do início do processo de secagem, as amostras foram lavadas (de acordo com a NBR-8428) com água fervente e mergulhadas em água destilada durante $2 \mathrm{~h}$.

\subsubsection{Módulo experimental}

A secagem convectiva foi realizada em um secador de túnel de convecção forçada desenvolvido por Cassandre et al. (2011). A linha experimental consiste de um sistema de escoamento de ar, onde um soprador (1) do tipo compressor radial (IBRAN) de $0,75 \mathrm{HP}$ impulsiona ar para as duas válvulas (2) do tipo gaveta, em que uma é usada para regular a vazão do ar e a outra para regular a vazão que retorna através de um reciclo para a tubulação de alimentação do soprador. $\mathrm{O}$ ar é aquecido em um aquecedor elétrico (3) dotado de 3 resistências elétricas de $750 \mathrm{~W}$ cada uma conectada a um variador de potência VARIVOLT (4). Quando houve a necessidade do resfriamento do ar de secagem, foi utilizado um trocador de calor (5) do tipo aletas, com dimensões de $D_{i n}=7,62 \mathrm{~cm}$ e $D_{e x}=5,02 \mathrm{~cm}$, que se encontra instalado, antes da entrada da câmara de secagem.

Para garantir a homogeneização do escoamento do ar, foi instalado na entrada da linha um conjunto de telas defletoras (6).

Após o escoamento desse ar pela câmara (7), é monitorada a perda de massa da amostra através de uma balança analítica digital, GEHAKA, do modelo BG 400 com precisão de 0,0001 g (8) acoplada ao secador, onde a medição é realizada em intervalos de tempo estabelecidos. $\mathrm{O}$ ar passa por um desumidificador, que consiste de um leito fixo de sílica gel (9) com dimensão de $D_{i n}=15,24$ $\mathrm{cm}$ e $0,50 \mathrm{~m}$ de comprimento.

Após passar pelo desumidificador, o ar, é recirculado para a linha.

As condições experimentais utilizadas nos ensaios foram: velocidade do ar de secagem de 1 e $2 \mathrm{~m} / \mathrm{s}$, monitorada com o auxílio de um anemômetro digital da marca ALNOR. Para o monitoramento da temperatura $\left(50,60\right.$ e $\left.70^{\circ} \mathrm{C}\right)$ no processo, foram instalados termopares do tipo $\mathrm{J}$ no interior da câmara de secagem, próximos a amostra.

$\mathrm{Na}$ Figura 2 é representado esquematicamente a linha experimental utilizada. Os ensaios foram realizados no DEQ/UFSCar. 
Figura 2 - Secador de túnel de convecção forçada

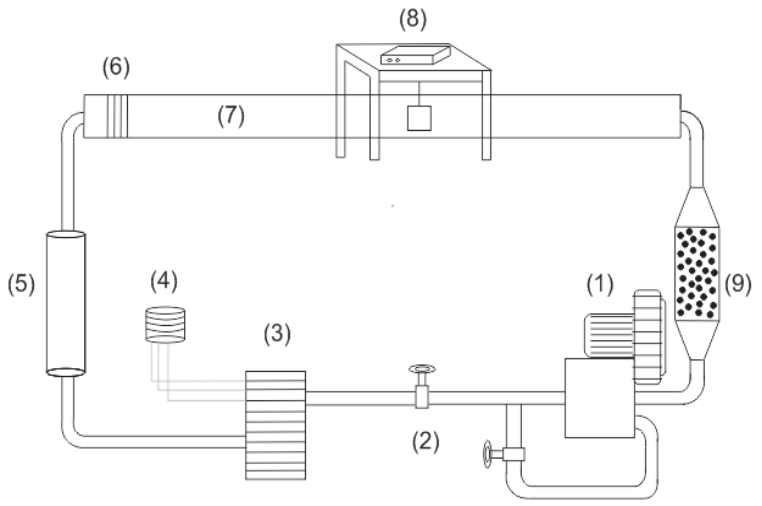

Fonte: Autor, (2015)

\subsubsection{Caracterização do material}

Foram determinadas as principais propriedades físicas de cada material como a espessura, gramatura e massa específica.

A gramatura, característica que determina a textura do tecido, foi obtida segundo a norma NBR 10.591- Materiais têxteis. Foram retirados 5 corpos de prova medindo $100 \times 100 \mathrm{~mm}$, de pontos diferentes da amostra de tecido. Para essa determinação de massa por unidade de área $\left(\mathrm{g} / \mathrm{m}^{2}\right)$, foi feita a média das pesagens utilizando uma balança com precisão de $0,0001 \mathrm{~g}$.

A espessura (E) das amostras de tecidos, foi determinada utilizando um paquímetro digital (espessura, comprimento e largura).

Para a determinação do diâmetro dos fios, foi utilizada a Equação 1, seguindo a norma ABNT 13.514:

$\mathrm{N}_{\mathrm{e}}=\frac{0,59 \cdot c}{m}$

em $N_{\mathrm{e}}$ é o título de fios, $m$ é a massa da amostra (g), c é o comprimento (m) e 0,59 é uma constante, quando se tem o peso em gramas e o comprimento em metros.

\subsubsection{Curvas generalizadas de secagem}

No tratamento das curvas de cinética de secagem do presente trabalho, aplicou-se a metodologia de curvas generalizadas, que consiste em reunir os resultados experimentais de cinética obtidos em diferentes condições operacionais, em curvas únicas. De acordo com Motta Lima, Pereira e Mendes (2002), essa metodologia relaciona a umidade adimensional das amostras, definida conforme a Equação 2 e uma variável adimensional de tempo (Equação 3), definida a partir da taxa constante de secagem e da umidade inicial.

$$
\begin{aligned}
& Y=\frac{X}{X_{O}} \\
& t_{a d}=\frac{N_{c} \cdot t}{X_{O}}
\end{aligned}
$$

onde, $X$ é a umidade adimensional (b.s), $X_{o}$ é a umidade inicial, $N_{c}$ é a taxa constante e $t$ é o tempo.

Para o ajuste dos resultados, foram avaliadas as equações mais utilizadas na literatura para a descrição de curvas de cinética de secagem, sendo elas eles: Page (1949) (Equação 4), Page modificado (Equação 5) e Overhultz et al., (2003) (Equação 6). Na Tabela 1, são mostrados a equações avaliadas nesse trabalho, com as variáveis adaptadas segundo a metodologia das curvas generalizadas.

Tabela 1- Modelos matemáticos.

\begin{tabular}{lc}
\hline \multicolumn{1}{c}{ Modelo } & Equação \\
\hline Page (1949) & $Y=\exp \left[-k \cdot t_{a d}{ }^{n}\right]$ (4) \\
Page & $Y=\exp \left(-k \cdot t_{a d}\left(a * t_{a d}+b\right)+\right.$ \\
modificado & 0,01
\end{tabular}

Overhultz et

al., (1973) $\quad Y=\exp \left[-k \cdot t_{a d}\right]^{n}$

Fonte: Autor, (2015).

\section{RESULTADOS E DISCUSSÃO}

\subsection{Caracterização do material}

As propriedades dos tecidos determinadas experimentalmente são apresentadas na Tabela 2. 
Tabela 2- Dimensões e propriedades estruturais do tecido de algodão-atoalhado, algodão-jeans e poliéster.

\begin{tabular}{llll}
\hline Estrutura & Atoalhado & Jeans & Poliéster \\
\hline $\begin{array}{l}\text { Espessura } \\
(\mathrm{mm})\end{array}$ & 0,90 & 0,70 & 0,95 \\
$\begin{array}{l}\text { Gramatura } \\
\left(\mathrm{g} / \mathrm{m}^{2}\right)\end{array}$ & 480,8 & 578,1 & 330,4 \\
$\begin{array}{l}\text { Diâmetro } \\
\text { dos fios } \\
(\mathrm{mm}) \text { 28,84 }\end{array}$ & 31,87 & 24,66 \\
\end{tabular}

Fonte: Autor, 2015.

Os tecidos de algodão utilizados são, tecidos planos que apresentam uma estrutura de entrelaçamento dos fios (trama e urdume) do tipo tela. Porém, o tecido de algodão do tipo atoalhado apresenta uma estrutura composta com laçadas sobre uma estrutura base, como pode ser observado na Figura 3a. Já no tecido de poliéster, não foi possível identificar uma estrutura definida, como pode ser observado na Figura 3.c.

Figura 3 - Análise da estrutura do tecido: (a) algodão-atoalhado; (b) algodão-jeans e (c) poliéster.

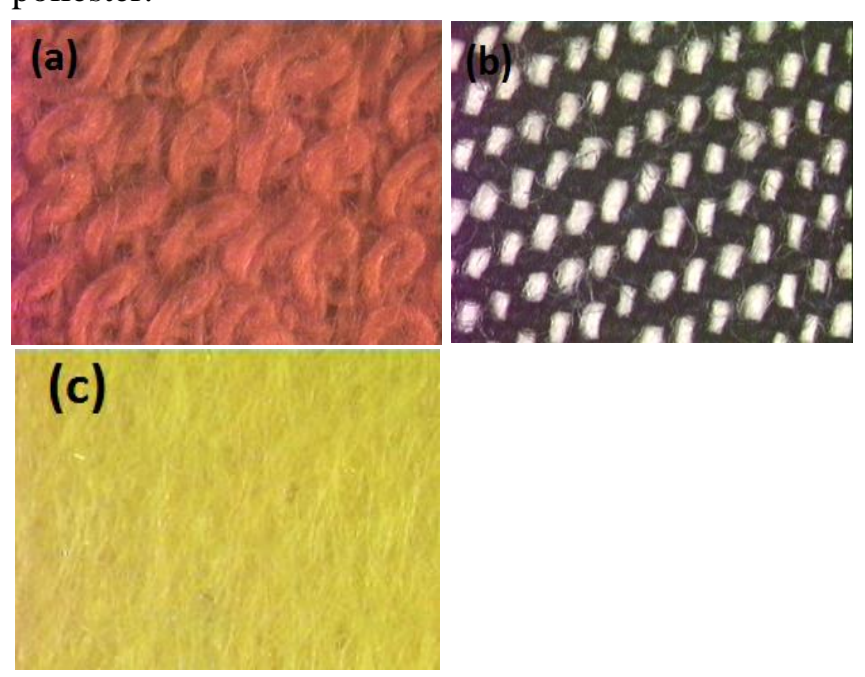

Fonte: Autor, 2015.

Segundo a Tabela 2, o tecido jeans é o de maior gramatura, o que significa que possui menores espaços entre os fios de trama e urdume do que as do tecido atoalhado e poliéster, ou seja, sua estrutura é mais "encorpada", porém sua espessura é menor. O poliéster possui a menor gramatura e espessura similar ao do tecido atoalhado.

\subsection{Cinética de secagem}

Para um melhor entendimento do processo, curvas típicas de cinética de secagem serão apresentadas para os três tipos de materiais, com o propósito de verificar a influência das diferentes condições operacionais no processo de secagem.

Nas curvas de cinética de secagem será utilizada a definição de umidade adimensional dada pela Equação 7:

$M R=\frac{X-X_{e q}}{X_{o}-X_{e q}}$

em que, $X$ é a umidade adimensional (b.s), $X_{o}$ é a umidade inicial (b.s) e $X_{e q}$ é a umidade de equilíbrio "dinâmico".

$\mathrm{Na}$ Figura 4, é apresentada a razão de umidade em função do tempo de secagem na condição de 50,60 e $70^{\circ} \mathrm{C}$ na velocidade de 1 $\mathrm{m} / \mathrm{s}$ para o tecido de poliéster.

Figura 4- Curvas de umidade adimensional em função do tempo, parametrizadas na temperatura, a velocidade de $1 \mathrm{~m} / \mathrm{s}$ para o tecido de poliéster

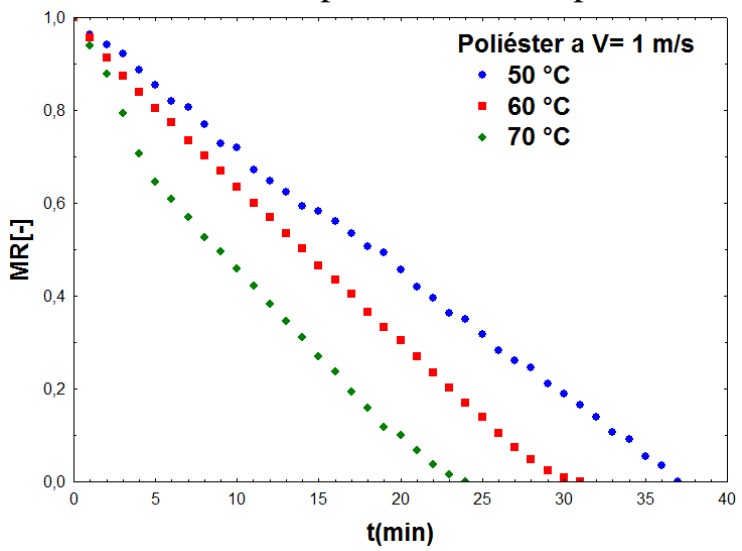

Fonte: Autor (2015).

Conforme a Figura 4, observa-se que a redução de umidade a uma velocidade constante do ar de secagem, aumenta com o 
aumento da temperatura. Com isso, é verificado que, como esperado, houve influência da temperatura na secagem. Por exemplo, aumentando-se a temperatura de 50 ${ }^{\circ} \mathrm{C}$ para $70{ }^{\circ} \mathrm{C}$ houve uma redução no tempo de secagem em aproximadamente $35 \%$.

Para a avaliação dos mecanismos envolvidos na secagem do tecido de poliéster, é apresentada na Figura 5, a curva da taxa de secagem em função da umidade em base seca.

Figura 5- Taxa de secagem em função da umidade em base seca na velocidade de $1 \mathrm{~m} / \mathrm{s}$ para o tecido de poliéster.

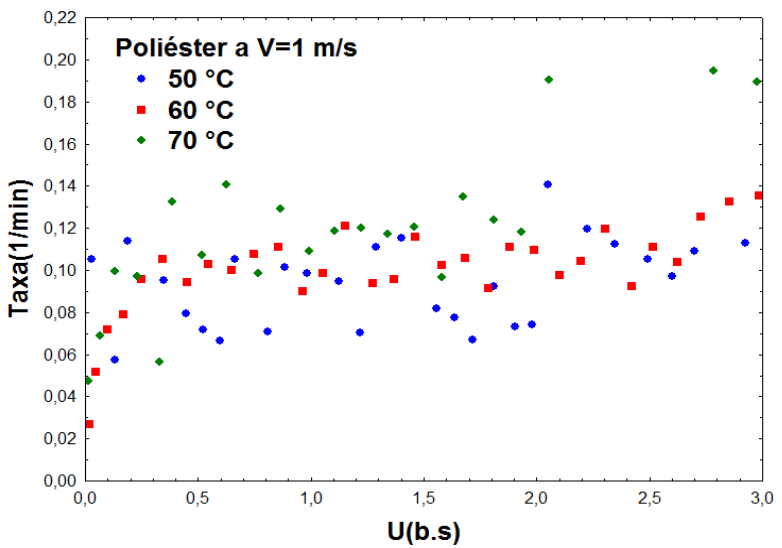

Fonte: Autor (2015).

Analisando-se a Figura 5, observa-se que, nas três condições de temperatura estudada, há a presença de um único período na secagem desse tipo de material, o período de taxa constante. Confirma-se também que, em média, o aumento da temperatura proporciona maiores taxas de secagem, embora o aumento não seja muito expressivo em termos quantitativos. $\mathrm{O}$ aumento da temperatura favorece $\mathrm{o}$ processo porque aumenta a pressão de vapor de água na interface.

Com base na constatação de secagem a taxa constante, pode-se afirmar que ocorre somente a remoção da água livre no material, ou seja, a energia consumida é usada na evaporação da água. Este comportamento está de acordo com o esperado para o poliéster, já que este tipo de tecido absorve pouca umidade, e a água superficial é facilmente removida. Neste caso a resistência ao transporte de umidade encontra-se na interface sólido-ar, logo confirmando, que a resistência convectiva é o mecanismo controlador em todo o processo de secagem do tecido de poliéster.

Convém observar também que os resultados apresentam dispersão elevada. Isto ocorre porque as taxas são estimadas derivando-se localmente as curvas de umidade em função do tempo. Como a variação de umidade é grande para pequenos intervalos de tempo, pequenos erros na determinação da umidade podem causar desvios significativos na estimativa das taxas.

Na Figura 6 é mostrada a razão de umidade em função do tempo parametrizada na velocidade do ar de secagem a uma temperatura constante para $\mathrm{o}$ tecido de poliéster, afim de verificar o efeito da velocidade do ar na secagem no processo de secagem.

Figura 6- Curvas de umidade adimensional em função do tempo parametrizada na velocidade, para a temperatura de $50{ }^{\circ} \mathrm{C}$ para o tecido de poliéster.

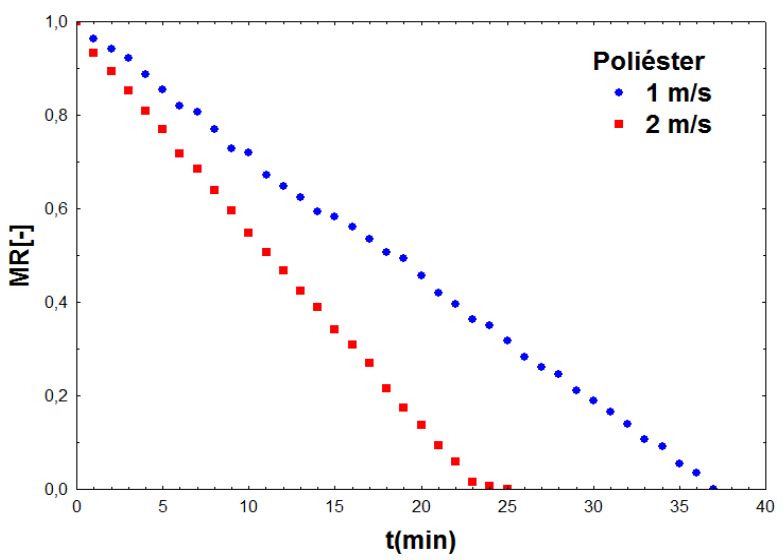

Fonte: Autor (2015).

Observa-se através da Figura 6, que o aumento da velocidade faz com que a cinética de secagem ocorra de forma mais rápida, comportamento esperado. Pois para esse tipo de tecido, durante todo o processo de secagem é a resistência interfacial que limita a transferência de umidade no material, logo, o aumento de velocidade favorece a redução da umidade, uma vez que a resistência diminui com o aumento da velocidade do ar. Isto está relacionado com a formação da camada limite 
na interface, onde ocorre o transporte de vapor da superfície do material para o ar. Ao se aumentar a velocidade do ar a espessura da camada limite diminui, diminuindo também a resistência interfacial externa.

Com o mesmo propósito de verificar a influência de diferentes condições no processo de secagem, é mostrada na Figura 7 as curvas de umidade adimensional em função do tempo para o tecido de algodão do tipo atoalhado.

Figura 7- Curvas de umidade adimensional em função do tempo parametrizada na velocidade de 1 $\mathrm{m} / \mathrm{s}$ para o tecido de algodão-atoalhado.

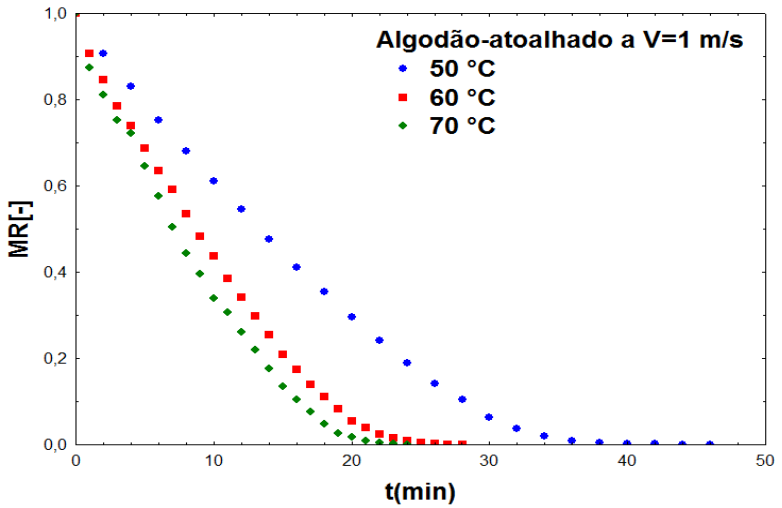

Fonte: Autor (2015).

Conforme a Figura 7, é visível a influência da temperatura na redução de umidade a uma certa velocidade constante do ar de secagem, onde nota-se, que a secagem realizada na temperatura de $50{ }^{\circ} \mathrm{C}$ é bem mais lenta que a realizada em $60^{\circ} \mathrm{C}$, obtendo-se uma redução no tempo de secagem de $39 \%$. Já aumentando a temperatura de $50{ }^{\circ} \mathrm{C}$ para $70{ }^{\circ} \mathrm{C}$ essa redução foi de aproximadamente $48 \%$. Porém, o aumento da temperatura de $60{ }^{\circ} \mathrm{C}$ para $70^{\circ} \mathrm{C}$ provocou apenas um aumento discreto na velocidade de secagem.

Em conjunto com essa análise, foram determinadas as curvas de taxa de secagem em função da umidade em base seca (Figura 8) para o tecido de algodão do tipo atoalhado, com o objetivo de avaliar os mecanismos envolvidos nesse processo.
Figura 8- Taxa de secagem em função da umidade em base seca na velocidade de $1 \mathrm{~m} / \mathrm{s}$ para o tecido de algodão-atoalhado.

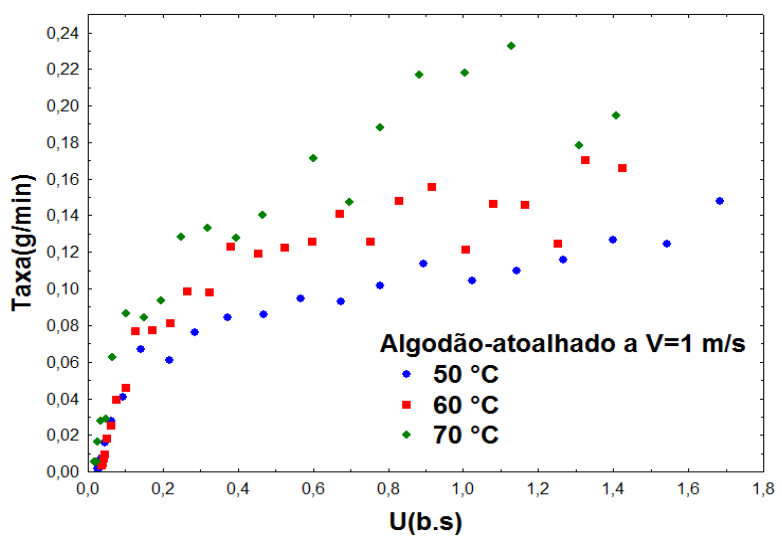

Fonte: Autor (2015).

Analisando a variação da taxa de secagem realizada a $50{ }^{\circ} \mathrm{C}$, observa-se que o período inicial de taxa constante nessa condição não é bem caracterizado, pois foi observado desde o início um comportamento decrescente da taxa de secagem. Inicialmente, entre as umidades de 1,8 (b.s) e aproximadamente 0,40 (b.s), a diminuição ocorre de forma lenta, e no final da secagem, ao atingir a umidade crítica (cerca de 0,1 b.s.) ela passa a diminuir rapidamente com o tempo, com o comportamento característico da secagem controlada por mecanismos internos de migração de umidade, até atingir a umidade de equilíbrio "dinâmica" (cerca de 0,03 b.s). Como este comportamento se repetiu em outras repetições deste ensaio, avalia-se que pode estar associado à estrutura composta do tecido, que possui uma camada superposta de fibras sobre a estrutura base, formando uma superfície irregular, o que pode resultar em uma resistência não uniforme para a remoção da umidade desde o início da secagem.

$\mathrm{Na}$ secagem realizada a $60{ }^{\circ} \mathrm{C}$ e $70{ }^{\circ} \mathrm{C}$ observa-se períodos de taxa constante até atingir a umidade crítica de 0,40 e 0,30 (b.s), respectivamente. Após atingir a umidade crítica, inicia-se o período de taxa decrescente bem acentuada, que se mantém até o final da secagem, quando o material atinge a umidade de equilíbrio "dinâmica, de 0,03 e 0,02 respectivamente. Nesse período final, a 
resistência interna passa a ser a etapa limitante no transporte de umidade.

Para todas as condições $\left(50,60\right.$ e $\left.70^{\circ} \mathrm{C}\right)$, o período de taxa decrescente característico do processo limitado pela resistência interna foi observado apenas próximo ao final da secagem, quando é retirada a umidade ligada à estrutura do material. $\mathrm{Na}$ maior parte do tempo, o processo de secagem no tecido de algodão do tipo atoalhado é controlado pela resistência convectiva na interface sólido-ar.

$\mathrm{Na}$ Figura 9, é mostrada o efeito da velocidade na secagem deste material através da curva de umidade em função do tempo de secagem.

Figura 9- Curvas de umidade adimensional em função do tempo parametrizada na velocidade, para a temperatura de $50{ }^{\circ} \mathrm{C}$ para o tecido de algodão do tipo atoalhado.

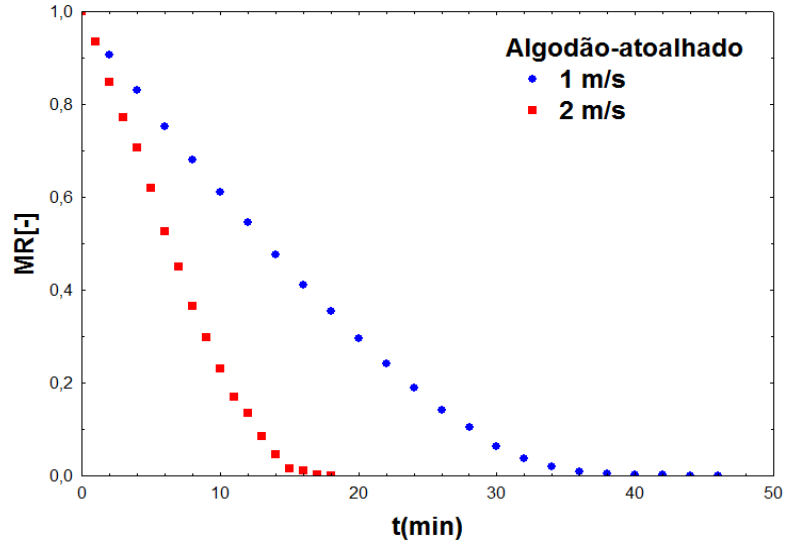

Fonte: Autor (2015).

Analisando a Figura 9, observa-se que o aumento da velocidade do ar de secagem teve efeito significativo, diminuindo de maneira mais rápida a cinética de secagem. Pelo fato da convecção ser o mecanismo limitante na maior parte do processo também para o tecido atoalhado, como discutido na análise da Figura 8 , esse aumento de velocidade se torna benéfico, pois reduz a resistência interfacial à transferência de massa.

Na Figura 10 são mostradas as curvas de cinética de secagem construída a partir dos resultados obtidos nas diferentes condições para o tecido de algodão do tipo jeans.
Figura 10- Curvas de umidade adimensional em função do tempo parametrizada na temperatura velocidade de $1 \mathrm{~m} / \mathrm{s}$ para o tecido de algodão do tipo jeans.

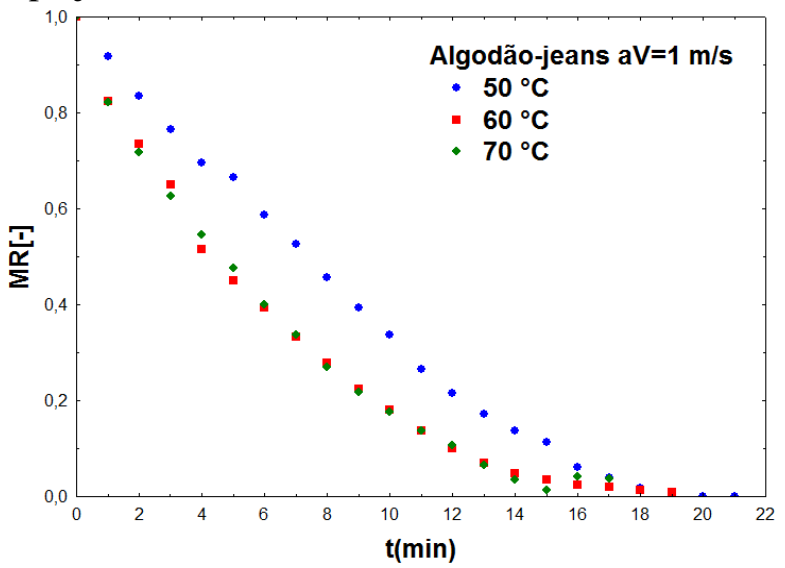

Fonte: Autor (2015).

Analisando a Figura 10, comparando a condição de $50{ }^{\circ} \mathrm{C}$ e $70{ }^{\circ} \mathrm{C}$, verifica-se uma influência da temperatura no processo e esse aumento conduz uma maior variação da massa provocando uma redução no tempo da secagem $(19 \%)$ do material, atingindo mais rapidamente a umidade de equilíbrio.

Quando comparado os resultados experimentais nas temperaturas de $60^{\circ} \mathrm{C}$ e $70^{\circ} \mathrm{C}$, percebe-se uma sobreposição das curvas, indicando que nesta faixa de variação, o aumento da temperatura não favoreceu o processo. Na Figura 11 é mostrada a curva da taxa de secagem em função da umidade em base para o tecido de algodão-jeans.

Figura 11- Taxa de secagem em função da umidade em base seca na velocidade de $1 \mathrm{~m} / \mathrm{s}$ para o tecido de algodão do tipo jeans.

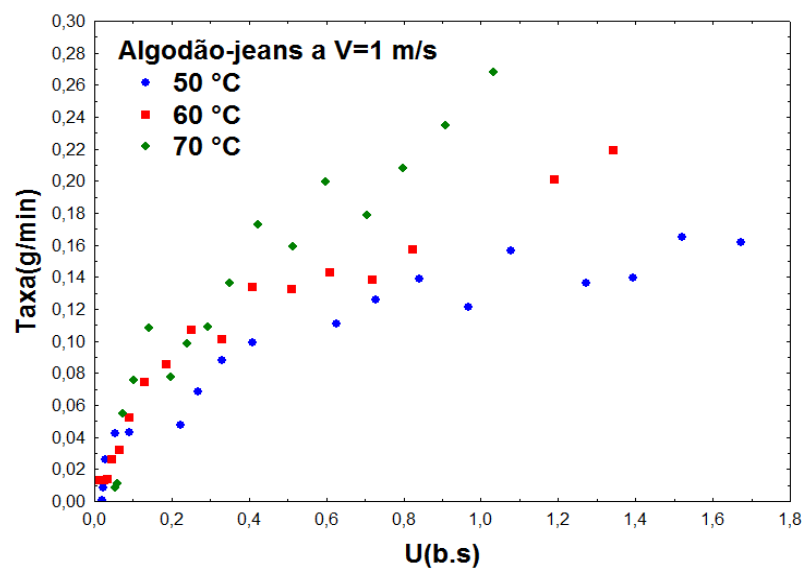

Fonte: Autor (2015). 
Analisando as curvas da taxa de secagem da Figura 11, observa-se um efeito do aumento da temperatura, com maiores taxas de secagem, inclusive nas temperaturas de $60 \mathrm{e}$ $70^{\circ} \mathrm{C}$. Observa-se, porém que este efeito aparece essencialmente no início da secagem, região em que a estimativa das taxas envolve mais incertezas, o que pode justificar está aparente discrepância em relação aos resultados da Figura 10.

O período de secagem a taxa decrescente é observado apenas no final da secagem, indicando que na maior parte do tempo o mecanismo de transferência de massa é o convectivo, para o qual o aumento da temperatura contribui pouco.

Para verificar o efeito da velocidade do ar na secagem deste material, é mostrada na Figura 12 a curva de umidade adimensional em função do tempo de secagem.

Figura 12- Cinética de secagem parametrizada na velocidade, para a temperatura de $50{ }^{\circ} \mathrm{C}$ para o tecido de algodão do jeans.

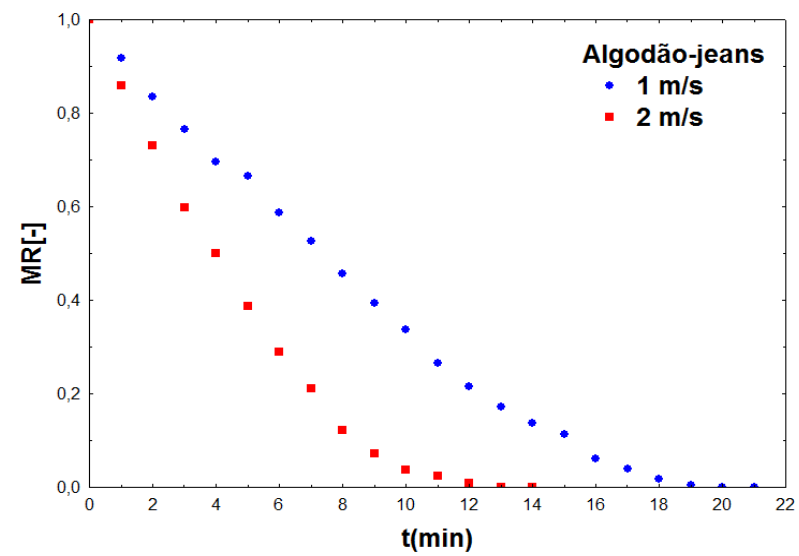

Fonte: Autor (2015).

Na condição apresentada na Figura 12, observa-se que o aumento da velocidade do ar provocou uma redução de $33 \%$ no tempo de secagem, ou seja, o efeito da velocidade na cinética de secagem é expressivo, pelos mesmos motivos já discutidos anteriormente. Com base nesse comportamento, é possível inferir que o mecanismo convectivo de transferência de umidade é predominante na secagem de tecido do tipo jeans.
Para uma análise comparativa do processo de secagem nos três diferentes tecidos, foi escolhida a cinética de secagem na temperatura de $50{ }^{\circ} \mathrm{C}$ e velocidade de $2 \mathrm{~m} / \mathrm{s}$, mostrada na Figura 13.

Figura 13- Curvas de umidade adimensional em função do tempo parametrizada na temperatura de $50{ }^{\circ} \mathrm{C}$ a velocidade de $2 \mathrm{~m} / \mathrm{s}$.

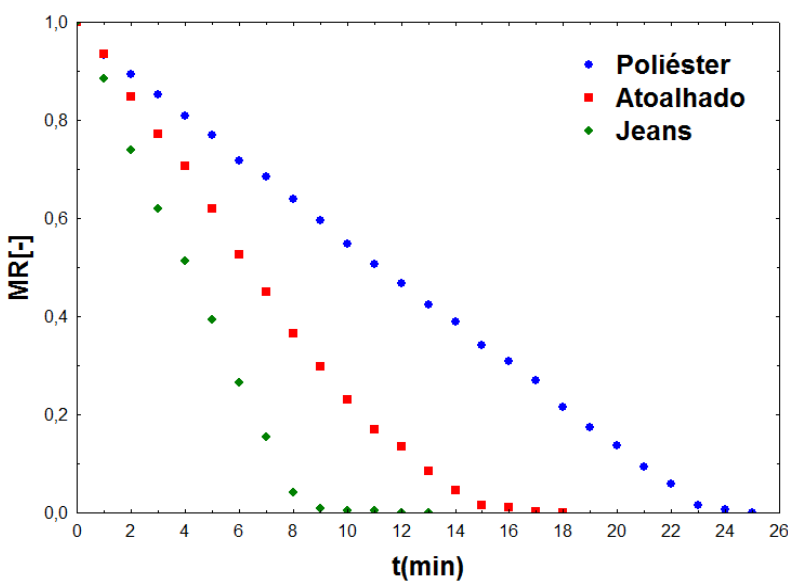

Fonte: Autor (2015).

Analisando-se a Figura 13, em uma primeira análise não era esperado que o tecido de poliéster apresentasse a secagem mais lenta, pois é o material que apresenta umidade mais livre, o que se nota pela variação linear da curva de MR em função do tempo ao longo de todo o processo. Porém, quando analisados os três tipos de tecidos, constatou-se que o mecanismo predominante no transporte de massa foi o mecanismo convectivo, que está associado às condições na interface amostraar.

Nesta velocidade, o número de Reynolds do escoamento é da ordem de $8 \times 10^{3}$, um valor relativamente baixo.

Comparando-se as texturas dos diferentes tecidos (Figura 3), nota-se que os tecidos de algodão (atoalhado e jeans), com estrutura do tipo trama, na qual fibras ficam mais expostas ao escoamento, possuem superfícies mais irregulares em relação ao poliéster. A rugosidade da superfície contribui para aumentar a área superficial e a intensidade de turbulência no escoamento, fatores que 
contribuem para aumentar as taxas de transferência de massa.

\subsection{Ajuste de equações de cinética de secagem}

A partir dos resultados experimentais em diferentes condições operacionais, foi aplicada a metodologia proposta por Motta Lima para a obtenção de curvas generalizadas de secagem nos tecidos de algodão do tipo atoalhado (Figura 14) e jeans, com o propósito de reunir os resultados das três temperaturas $\left(50,60\right.$ e $\left.70^{\circ} \mathrm{C}\right)$ e duas velocidades $(1$ e $2 \mathrm{~m} / \mathrm{s})$ em curvas únicas.

Figura 14- Curva generalizada de secagem para o tecido de algodão-atoalhado

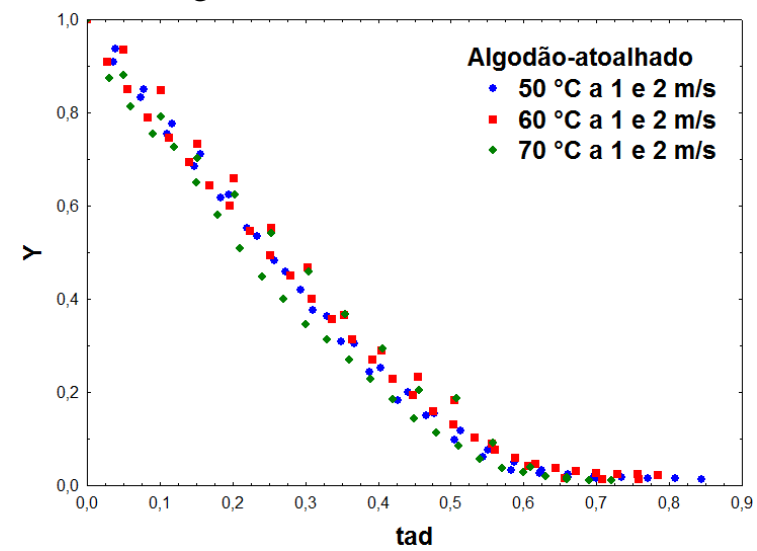

Fonte: Autor (2015).

Para o tecido jeans, os resultados também foram tratados através da metodologia das curvas generalizadas, a qual apresentaram comportamento similar ao da Figura 14.

Após feita a generalização das curvas da cinética de secagem, foram efetuados ajustes com equações clássicas de cinética de secagem à essas curvas. Os modelos utilizados foram: Page (1949), Page Modificado e Overhultz et al., (1973).

Na Figura 15a. e b é mostrado o ajuste de modelo que melhor se ajustou aos resultados experimentais para os tecidos de algodão do tipo atoalhado e jeans, respectivamente.
Figura 15- Ajuste da curva generalizada de secagem pelo modelo de Page Modificado para o tecido atoalhado (a) e jeans (b).
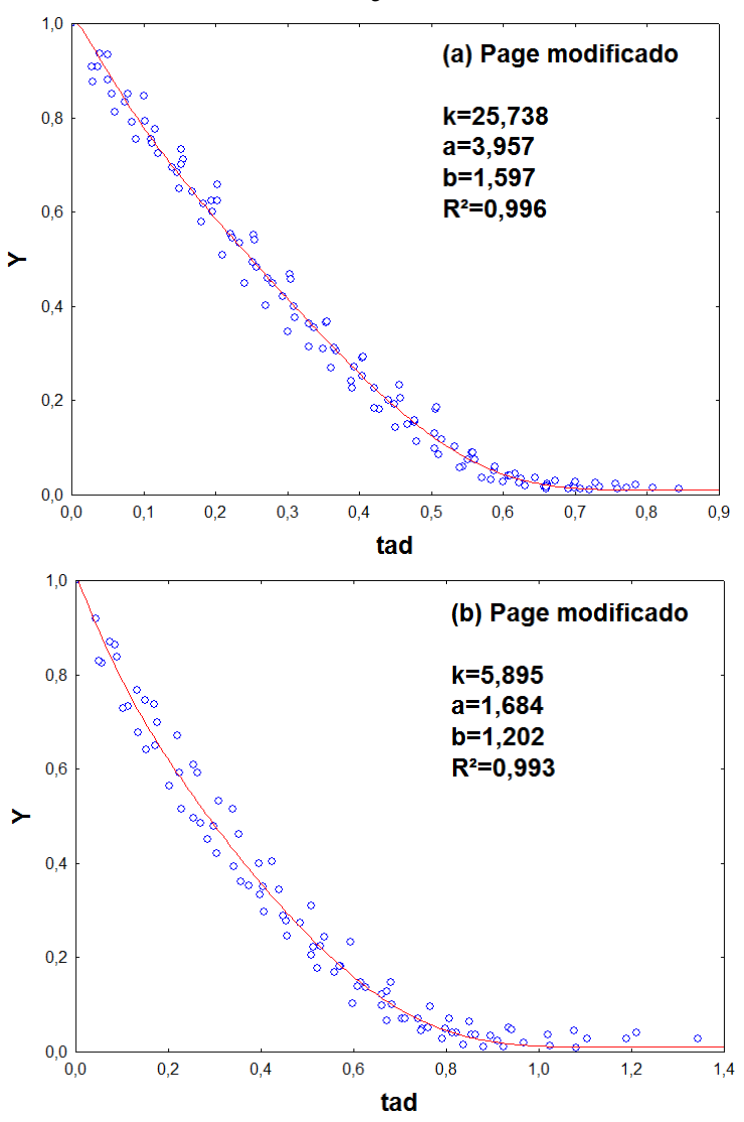

Fonte: Autor (2015).

Através das Figuras 15a e $15 \mathrm{~b}$ é mostrado, que tanto o tecido atoalhado quanto o jeans, o modelo que apresentou o melhor ajuste aos resultados experimentais foram os originados pelo modelo de Page modificado, apresentando um $\mathrm{R}^{2}$ de 0,996 e 0,993, respectivamente. Este melhor ajuste, está relacionado com o número de parâmetros que a equação apresenta e isso proporcionou um maior número de graus de liberdade para a equação, tornando o ajuste mais adequado aos resultados.

\section{CONCLUSÃO}

$\mathrm{Na}$ secagem dos tecidos de algodão e poliéster avaliados, foi observado a 
predominância do mecanismo convectivo de transporte de umidade. Neste mecanismo, a resistência interfacial é predominante na transferência de massa, e assim, a velocidade do ar apresentou influência significativa no processo de secagem. As taxas de transferência aumentaram com o aumento da velocidade de escoamento. Como é controlada pelas condições na superfície, para idênticas condições de velocidade e temperatura, a secagem foi mais rápida para os tecidos de algodão, cuja textura na superfície é irregular devido ao tipo de estrutura do tecido.

Dentre as equações avaliadas para ajustar os resultados experimentais para a secagem de tecidos de algodão, a equação que apresentou boa concordância com os resultados experimentais para ambos os casos, foi a de Page modificado.

\section{NOMENCLATURA}

$a, b$, parâmetros nas equaçõe

$\mathrm{k}$ e $\mathrm{n}$ cinéticas

$D_{\text {in }}$ diâmetro interno

$D_{\text {ex }} \quad$ diâmetro externo

E espessura

$\mathrm{T}$ temperatura do ar de

secagem

$t_{\text {ad }} \quad$ tempo adimensional

$\mathrm{V}$ velocidade do ar de [L/T] secagem

$\mathrm{X}$ umidade adimensional (b.s)

$X_{O} \quad$ umidade inicial (b.s)

MR razão de umidade adimensional

Y
CASSANDRE, J. E. F.; MOREIRA, M. F. P.; SARTORI, D. J. M. Desenvolvimento de um secador de convecção forçada com reciclo de ar. In: III COBEQ-IC, 3, 2001, Belo Horizonte. Anais ...

CSERI, D. Fundamentos de malharia: estudo do fator de elasticidade em tecidos de malha e suas aplicações. Maio de 2014.Disponível em: $<$ http://pt.slideshare.net/debcseri/fundamentos -de-malharia-estudo-do-fator-de-elasticidade> Acesso em: 5 de jun. 2015.

FIRJAM, A. A., FERRAZ, F. T. Uma breve análise acerca do segmento industrial têxtil e de confecção brasileiro pós década de 80 e a competitividade do setor no mercado de Juiz de Fora, MG. Redige, v.2, n.3, p. 23-41, 2011.

MOTTA LIMA, O. C., PEREIRA, N. C., MENDES, E. S. Curvas generalizadas na análise da cinética de secagem de papel artesanal com ar ambiente em convecção forçada. Acta Sci. Technol., v. 25, n.1, p. 4552, 2003.

\section{REFERÊNCIAS}

ALBUQUERQUE, W. M. S. Estudo da secagem de tecido jeans. 2011. 91f. Dissertação (Mestrado em Engenharia Mecânica) - Universidade Federal de Pernambuco, Pernambuco, 2011. 